\title{
Decentralizing Aid with Interested Parties
}

\author{
Gil S. Epstein \\ (Bar Ilan University, Ramat Gan, IZA, Bonn and CReAM, London) \\ epsteig@mail.biu.ac.il \\ Ira N. Gang \\ (Department of Economics, Rutgers University) \\ gang@economics.rutgers.edu
}

This Version: July 31, 2006

\begin{abstract}
This paper analyzes the decentralization of decision-making in aid-giving in a theoretical rent-seeking framework. In this analysis the root donor establishes a necessary criterion for potential recipients: good governance. The potential recipients compete in hierarchal contests for funds. The paper investigates whether, under certain reasonable conditions, fashionable aid procedures will lead to the development of a poverty trap.
\end{abstract}

Keywords: foreign aid, governance, decentralization, rent seeking JEL Classifications: O10, O19, F35, O11, C23, O47, E21, E22

Correspondence: Ira Gang, Economics Department, Rutgers University, 75 Hamilton St, New Brunswick NJ 08901-1248 USA. email: gang@economics.rutgers.edu Tel : +1 732932-7405. Fax : +1 732-932-7416.

This paper was presented at the conference "Development Aid: A Fresh Look” UNU-WIDER Project Meeting, 16-17 September 2005, Helsinki. We thank the participants for their comments. 


\section{Decentralizing Aid with Interested Parties}

\section{Introduction}

Due to a multitude of domestic and international political and economic forces, over the last three to four decades it became prudent for many national development agencies to develop something of an arms length relationship towards their aid activity. The standard multilateral institutions had taken up some of this in the 1970s, and in the process changed the bonds between root donors and recipients, altering the roles and effectiveness of both bilateral and multilateral institutions. However, by the 1990s the standard multilateral institutions had their own reputation issues. Donor governments and multilateral institutions began to rely heavily on non-government organizations (NGOs) to allocate aid and to implement their aid projects/programs. ${ }^{1}$ Since NGOs usually have well-defined goals, donor government policy is achieved by funding the NGOs which have similar mindsets.

At the same time, it became popular to discuss economic development in terms of developing the proper set of institutions - including the legal framework and social conventions. International aid was brought into this discussion because of its influence on institutional development and its impact on growth and other development indicators. While not universally embraced, a stylized fact of development policy became that good governance is a necessary pre-requisite for aid to be effective in terms of raising a nation's rate of growth. $^{2}$

Together the movement by root donors towards more arms-length relationships with the aid process and the new light shone on the role of governance in implementing proper policies has had a big impact on both the discussion and implementation of development

${ }^{1}$ During the 1990s the numbers and roles of international nongovernmental organizations (NGOs) taking part in the foreign aid process grew. For all the Development Assistance Committee (DAC) countries, official development assistance (ODA) to NGOs increased from US\$928 millions in 1991-1992 to US\$1246 millions in 2002, and increase of $34 \%$. This represents an increase from 1.59 to $2.14 \%$ of all DAC ODA from 1991-1992 to 2002. For the United Kingdom, a country where this shift is quite stark, the funding of ODA to NGOs went from US $\$ 21$ to US $\$ 226$ millions, an increase of $976.2 \%$, and from $0.65 \%$ of all UK ODA in $1990-1991$ to $4.6 \%$ in 2002 . The number of international NGOs grew by $19.3 \%$ during the decade. See Epstein and Gang, 2006, for an analysis of the role of NGOs in the aid process.

2 See McGillivray, Feeny, Hermes and Lensink, 2005, for a review and analysis of the empirical work surrounding this change. Also see Heckelman and Knack, 2005, for an argument that aid retarded economic liberalization. 
policy. If good governance is necessary for the effective use of aid, then by allocating aid on the basis of a country achieving good governance becomes a "win-win" situation: aid is given where it will have an impact and objective criteria can be established. This will minimize the necessity for detailed bureaucratic planning, disbursement, and oversight, as aid is in part the reward for good governance and with good governance it is assumed aid will be channeled properly. The introduction into the US debate of the Millennium Challenge Account and the establishment of the Millennium Challenge Corporation arose from this environment. $^{3}$

This is a very powerful argument for decentralization - give aid only to those with good governance. The need for many levels of checks is reduced and the aid allocation decision is allowed to be made by those closest to the needs. We analyze this decentralization of decision-making in a theoretical rent-seeking framework. We model the aid allocation decision where the donor government has announced that good governance is the criterion for receiving aid. Potential recipients must therefore compete for the aid funds. We will show that the structure of the competition is important to the donor in terms of achieving good governance, and to the recipients in terms of what they receive. Potential recipients look at aid as part of their overall program. The governments, represented by their leaders, after all are the presumed beneficiaries of bad governance. Those implementing policy (the government or the leader) are explicit rent-seekers who consider aid as part of the total "package” available to them.

Our main result is that the donor country will prefer the system under which the aid will all go to only one country, while the leaders of the receiving countries will prefer that each country will obtain the proportion of aid relative to its governance quality. We also separate the donor's desire for poverty reduction, a consequence of which may be the development of a poverty trap. In order to continue to receive transfers based on a poverty measure a potential recipient government may deliberately allocate funds away from the poorest so as not to better their position. Incentives often work in non-obvious ways.

In Section 2, which constitutes the bulk of the paper, we present our major results. Section 3 examines the possibility of a poverty trap. Section 4 concludes.

${ }^{3}$ See Mavrotas and Villanger, 2006, for an alternative characterization of this process. 


\section{The Model}

Imagine a donor who had an exogenously fixed amount of aid funds to allocate among several potential recipients. The US Congress, for example, may set their aid budget with regard to other budgetary items. With this budget the aid agency decides how the funds should be divided among potential recipients. One strategy the aid agency might follow is to first decide what the regional allocations should be, and then how much each country within a region receives.

Potential recipient countries compete for aid funds. Each has a leader who hopes to benefit from the country's receiving aid. One can think of winning aid in probabilistic terms, with the expected benefit a country/leader receives in this competition equaling the probability of wining the aid multiplied by the total aid made available for the competition by the donor. One can also look at the probability of winning, not as a probability of winning all of the available aid but as the proportion of available aid that this country/leader receives. We generally talk about proportions of total aid obtained and not probabilities of winning aid, keeping in mind that the two are equivalent.

The donor decides to establish a rule requiring potential recipient countries to invest in governance quality. The more one invests the higher is the chance of receiving aid. We interpret the donor's ability to draw recipient country funds that would have been spent elsewhere into targeted objectives as aid's effectiveness. The usual sense of aid effectiveness is the degree to which aid funds are not fungible - that they do not stray from the donor's intended usage. Here we are more demanding, requiring aid to draw resources into good governance. Since the total amount of aid available is fixed, the greater the ability of the leader to move expenditures, the greater the opportunity for governance quality. Obviously, good governance is only one of many goals that donor's may define, but we keep with the recent literature in presuming that the donor chooses governance as the goal on the assumption that this ensures proper spending of aid funds.

Each leader invests effort in governance quality, with effort measured as the number or quality of changes in a country, or some other reasonable rubric. Investments made by all 
countries/leaders determine the proportion of the aid obtained (or the probability of winning the contest). ${ }^{4}$

We assume that investment in governance quality is costly to the leader. Investment in governance quality decreases the power of the leader; for example, the leader will have less control and perhaps as a result obtain fewer and smaller bribes. Therefore, the leader sees investment in governance quality as a reduction in his utility. However, investment in governance quality is part of a contest among countries to obtain aid. While the utility of the leader declines as more investment in good governance takes place (all else held constant), the potential for receiving aid funds raises the leader's expected utility (everything changing).

We now consider two possible types of cases in the allocation of aid between the different countries:

1. In the first scenario the country giving the aid, the donor, gives all the aid to only one country. Since the competition is over governance quality, in this case the donor country would give the aid to the country that invests the most effort in governance quality and thus has improved the most. In this scenario the recipient who "tries the hardest" is entitled to receive all of the donor's aid; expectations of aid is the incentive for the promotion of good governance.

2. In the second scenario the donor divides its aid proportionally among the potential recipient countries according to investments made by each of the leaders in governance quality. Thus each country receives aid based on its investment in governance quality invested relative to the investments of other competing countries.

To simplify the discussion we can think of each country having a fixed marginal cost set equal to one for each unit of governance quality invested by the leader. Thus, the expected net payoff (surplus) for the risk neutral leader of a country is simply the expected benefit (equaling the probability of wining the aid multiplied by the total aid available multiplied by the marginal value of the aid for the leader) minus the total investment in

\footnotetext{
${ }^{4}$ Just because one invests in good governance doesn't mean that it is obtained. Moreover, some countries may obtain good governance with smaller investments than other countries. Noting these caveats, we assume that investment in good governance is synonymous with obtaining good governance.
} 
governance quality. This is true for all countries participating in the competition to receive aid from the donor.

For this discussion, we need to assume that this framework satisfies several conditions regarding the proportion of the aid obtained in the contest (or the probability of winning the contest):

1. The sum of the proportions of the aid obtained equals one. This assumption tells us that all the aid is allocated in the end and nothing is left over for the donor to allocate in the next period. Moreover, the donor cannot allocate funds it does not have.

2. Given that all the other countries have a fixed amount of resources invested in governance quality, as leader of a country increases its effort in governance quality (with all the rest are not changing their investments), the country obtains a higher proportion of available aid. The idea here is that increasing the investment in governance quality increases proportion of available one can obtain.

3. As the leader of an opponent country makes increasing efforts to achieve governance quality, the proportion of available aid that the other leaders obtain decreases. Namely, if your opponents increase their quality of governance while you do not change your investments, then the proportion you receive decreases.

4. The marginal increase in the proportion of aid obtained from the contest decreases with investment in governance quality. The idea here is that there are decreasing returns to investment in governance quality in terms of obtaining aid.

The leaders of the countries engage in a contest over governance quality in order to obtain aid from the donor country. We assume a Nash equilibrium outcome. Each country determines the level of its governance quality, $x_{i}$, so that its expected payoff, $E\left(w_{i}\right) \forall i=1,2, . ., m$, is maximized. Denote by $\operatorname{Pr}_{i}$ the proportion of the rent $A$ that is received by country/leader $i$. Therefore, the expected payoff of country/leader $i$ out of $m$ countries is given by

$$
E\left(w_{i}\right)=\operatorname{Pr}_{i} A-x_{i} \forall i=1,2, \ldots, m,
$$


such that $\sum_{i=1}^{m} \operatorname{Pr}_{i}=1, \frac{\partial \operatorname{Pr}_{i}}{\partial x_{i}}>0, \frac{\partial \operatorname{Pr}_{i}}{\partial x_{j}}<0$ and $\frac{\partial^{2} \operatorname{Pr}_{i}}{\partial x_{i}^{2}}<0$.

The first order condition for maximization is given by

$$
\frac{\partial E\left(w_{i}\right)}{\partial x_{i}}=\frac{\partial \operatorname{Pr}_{i}}{\partial x_{i}} A-1=0
$$

The second order conditions are satisfied and equal to

$$
\frac{\partial^{2} E\left(w_{i}\right)}{\partial x_{i}^{2}}=\frac{\partial^{2} \operatorname{Pr}_{i}}{\partial x_{i}{ }^{2}} A<0
$$

Equation (2) is satisfied if and only if

$$
\frac{\partial \mathrm{Pr}_{i}}{\partial x_{i}}=\frac{1}{A}
$$

Thus, given that the proportion has decreasing marginal utility with respect to the level of governance quality, we obtain that if the marginal benefit from a dollar of aid increases then the country will invest more effort in governance quality.

\subsection{Aid given to one country only}

We now describe the situation where the donor gives all the aid to only one country. We assume the extreme situation that all the aid goes to the country that has undertaken the greatest investment in governance quality. In other words, the leader who invests in the highest level of governance quality receives the donor's entire aid allocation, $A$. The contest success function in this case is the all-pay auction where the country that invests the highest amount in governance quality wins all the aid; however those that do not win cannot revert to lower governance quality. While some part of the governance quality is reversible, not all of it is reversible. To simplify we assume that none of the investment in governance quality is reversible. 
The probability of winning the contest for the donor's aid is captured by a contest success function (CSF). The situation where the winner of the contest takes all available aid is captured by an all-pay auction. This is given by ${ }^{5}$

$$
\operatorname{Pr}_{i}=\left\{\begin{aligned}
& 1 \text { if } \quad x_{i}>x_{j} \forall i \neq j \\
& \frac{1}{k} \quad \text { if i ties for the highbid with }(k-1) \text { others } . \\
& 0 \quad \text { if } \quad x_{j}>x_{i} \forall i \neq j
\end{aligned}\right.
$$

It has been well-established that there exists a unique symmetric Nash equilibrium as well as a continuum of asymmetric Nash equilibria (see Baye, Kovenock, and de Vries, 1993). A standard result in this literature is that there are no pure strategy equilibria in all-pay auctions (Hillman and Riley (1989), Ellingsen (1991) and Baye, Kovenock and de Vries (1993)). It is also a standard result that there is no equilibrium in pure strategies in all-pay auctions. The expected investment in governance quality for each country is given by

$$
E\left(x_{i}^{*}\right)=A \frac{1}{m} \quad \forall i=1,2, \ldots, m .
$$

The equilibrium probability of winning the contest for the aid is the same for each country and equals

$$
\operatorname{Pr}_{i}^{*}=\frac{1}{m} \quad \forall i=1,2, \ldots, m
$$

The expected equilibrium payoff for each country equals

$$
E\left(w_{i}^{*}\right)=0 \quad \forall i=1,2, \ldots, m
$$

In equilibrium, the total amount of governance quality carried out by the countries (assuming one can add the components) equals

\footnotetext{
${ }^{5}$ Under this scenario thinking in terms of the probability of winning the contest enhances our intuition.
} 


$$
E\left(X^{*}\right)=E\left(\sum_{i=1}^{m} x_{i}^{*}\right)=A
$$

In the literature this measure is called rent dissipation.

\subsection{Aid proportionate to the governance quality of each country}

Here we consider the case where the leaders of the potential recipient countries compete with one another in a contest in which no one wins all the aid. In the general case there are $m$ countries competing against one another.

Each country under this contest for aid will receive funds proportional to the relative amount they have invested in governance quality. We assume that the contest is characterized by the Tullock (1980) contest success function (see also Lockard and Tullock, 2001),

$$
\operatorname{Pr}_{i}=\frac{x_{i}}{\sum_{j=1}^{m} x_{j}} \text { for } \forall i=1,2, . ., m
$$

This function states that each country receives aid funds proportional to their invested amount in governance quality compared to other countries.

The expected net payoff (surplus) for the risk neutral leader of country $i$ is thus given by

$$
E\left(w_{i}\right)=\operatorname{Pr}_{i} A n-x_{i}=\frac{x_{i}}{\sum_{i=1}^{m} x_{i}} A-x_{i} \quad i=1,2, \ldots, m
$$

The first order condition, as stated in equation (2), that ensures that the leaders of the countries maximize their expected payoff, is given by 


$$
\frac{\partial E\left(w_{i}\right)}{\partial x_{i}}=\frac{\sum_{j=1, j \neq i}^{m} x_{j}}{\left(\sum_{i=1}^{m} x_{i}\right)^{2}} A-1=0 \quad \forall i, j=1,2, \ldots, m i \neq j
$$

The second order conditions for maximization are given by

$$
\frac{\partial^{2} E\left(w_{i}\right)}{\partial x_{i}^{2}}=-2 \frac{\sum_{j=1, j}^{m} x_{j}}{\left(\sum_{i=1}^{m} x_{i}\right)^{3}} A<0 \quad \forall i, j=1,2, \ldots, m i \neq j
$$

Denote by $x_{i}^{*} \quad \forall i, j=1,2, \ldots, m i \neq j$ the Nash equilibrium outcome of the contest. Solving (12) for all leaders using a Nash equilibrium, we obtain that the level of governance quality activities for each participating country is

$$
x_{i}^{*}=A \frac{(m-1)}{m^{2}} \quad \forall i=1,2, \ldots, m .
$$

Therefore, in the Nash equilibrium, the proportion of aid obtained by each of the countries in this contest ${ }^{6}$ equals

$$
\operatorname{Pr}_{i}^{*}=\frac{1}{m} \quad \forall i=1,2, \ldots, m
$$

From (14) and (15) we obtain that the expected equilibrium payoff for each leader equals

$$
E\left(w_{i}^{*}\right)=\frac{A}{m^{2}} \quad \forall i=1,2, \ldots, m .
$$

And finally, assuming we can add up the amount of effort invested in governance quality by all participating countries, we can calculate the aggregate investment effort by these countries in governance quality. In our contest it tells us how much effort the leaders in

\footnotetext{
${ }^{6}$ Under this scenario our intuition is enhanced by thinking in terms of the proportion of the rents obtained from the contest.
} 
the countries have invested in governance quality in order to increase the proportion of aid obtained from the donor country.

We denote this total effort invested (rent dissipation) in governance quality in equilibrium by $X^{*}$,

$$
X^{*}=\sum_{i=1}^{m} x_{i}^{*}=A \frac{m-1}{m}
$$

\subsection{Comparing aid to one country and proportional aid}

We now wish to compare these two types of contests from the perspectives of both the donor and the leaders of the potential recipient countries. The donor is concerned with the level (the quantity and intensity) of the quality of governance in potential recipient countries. It wishes to find a contest that will maximize the amount of governance quality for a given level of aid. The receiving leaders wish to have a contest that will maximize their expected net payoffs. Let us therefore compare both systems and see which is better from the perspectives of the donor and of the leaders of the receiving countries.

When aid is allocated to only one country, we obtain from (6), (7) and (8), $\forall i=1,2, \ldots, m$ :

$$
E\left(x_{i}^{*}\right)=A \frac{1}{m}, \operatorname{Pr}_{i}^{*}=\frac{1}{m}, E\left(w_{i}^{*}\right)=0 \text { and } X^{*}=A n
$$

When aid is awarded proportionate to investments in governance quality, we obtain from (14), (15) and (16), $\forall i=1,2, \ldots, m$ :

$$
x_{i}^{*}=A \frac{(m-1)}{m^{2}}, E\left(w_{i}^{*}\right)=\frac{A}{m^{2}}, \operatorname{Pr}_{1}^{*}=\frac{1}{m}, X^{*}=A \frac{(m-1)}{m}
$$

Thus,

1. In both cases the probability/proportion of aid received by each country is identical to one over the number of countries competing. 
2. Each country invests more resources in governance quality when all the aid goes to one country.

3. Each leader has a higher expected payoff when each country receives aid proportionate to their investment effort in governance quality. The more one invests the higher is the chance of receiving aid. The more fungible are non-aid funds, the easier it is for the leader of a country to turn around the governance system and embark on the path towards higher quality. Therefore, requiring that a country have higher governance quality helps channel resources appropriately. Since the total amount of aid is fixed, the situation that maximizes the quality of governance increases the flexibility of non-aid funds. It is important to notice that even if only one country is receiving aid, all countries are investing in governance quality. The return to aid, even though only one country is receiving it, is from all countries competing for the funds.

Since the donor wishes to maximize governance quality and the leaders of the countries wish to maximize expected payoffs, we obtain,

The donor country prefers a system under which aid is allocated to only one country, while the leaders of the potential recipient countries prefer a system under which each country receives a proportion of aid relative to its investment in governance quality.

\section{Poverty trap}

Though we have considered good governance as the pre-requisite for the effective use of aid, donors may try to achieve several goals simultaneously. For example, in addition to governance quality they may to directly address the immediate problem of poverty. Let $d_{i}$ be a parameter capturing how bad off the country is in terms poverty. We can think of $d_{i}$ as the number of poor or a more formal measure of poverty, where increasing $d_{i}$ indicates greater poverty. In order to compare our results to the ones presented above we restrict this analysis to the decentralized division of aid under which countries obtain aid in proportion to the level of investment in governance quality (as well as the poverty level). We do not analyze this in the system where all aid goes to one country as then we have to determine the criteria under which the "best" wins. This will give us many different possibilities and for each we would get different results. Thus in order for us to be able to compare the results 
obtained earlier we confine ourselves to the decentralized method under which each potential recipient receives a proportion of the aid.

Let the contest success function, the proportion of aid received by country $i$, be equal to,

$$
\operatorname{Pr}_{i}=\frac{d_{i} x_{i}}{\sum_{j=1}^{m} d_{j} x_{j}} \text { for } \forall i=1,2, . ., m
$$

Each country under this contest for aid receives funds proportional to investment in governance quality and the poverty level. The donor allocates aid based on the level of poverty (more poverty, more aid), making the probability of receiving aid increase with greater poverty. This contest success function is a variant of the Tullock (1980) contest success function (see also Epstein, 2000).

Each leader of each country invests in governance quality, $x_{i}$, and decides whether to invest in poverty reduction (lowering $d_{i}$ ) or not (either allowing poverty to stay the same or increase). The expected net payoff to the leader of country $i$ is given by

$$
E\left(w_{i}\right)=\frac{d_{i} x_{i}}{\sum_{j=1}^{m} d_{j} x_{j}} A-x_{i}-d_{j} \quad \forall i \neq j, i, j=1,2, . ., m .
$$

The first order conditions are given by ${ }^{7}$

$$
\frac{\partial E\left(w_{i}\right)}{\partial x_{i}}=\frac{d_{i} \sum_{j=1, i \neq j}^{m} d_{j} x_{j}}{\left(\sum_{j=1}^{m} d_{j} x_{j}\right)^{2}} A-1=0 \quad \forall i \neq j, i, j=1,2
$$

and,

${ }^{7}$ The second order conditions hold, $\frac{\partial E\left(w_{i}\right)}{\partial x_{i}}<0$ and $\frac{\partial E\left(w_{i}\right)}{\partial d_{i}}<0$. 


$$
\frac{\partial E\left(w_{i}\right)}{\partial d_{i}}=\frac{x_{i} \sum_{j=1, i \neq j}^{m} d_{j} x_{j}}{\left(\sum_{j=1}^{m} d_{j} x_{j}\right)^{2}} A-1=0 \quad \forall i \neq j, i, j=1,2
$$

Solving the first order conditions for both players we obtain that the optimal investment in governance quality and in poverty (that is, having poverty increased) equals,

$$
x_{i}^{*}==d_{i}^{*}=\frac{1}{2 m},
$$

and the probability of winning and the total expenditure on governance quality equals,

$$
X^{*}=\frac{1}{m} \text { and } \operatorname{Pr}_{i}^{*}=\frac{1}{m} \text {. }
$$

As we can see, in this example the results in terms of the donor country are identical to those we obtained when there was not an option to increase the proportion of aid received based on the poverty level. In both cases the leaders of the potential recipient countries invest the same amount of resources. Thus the leaders in both cases receive the same proportion of available aid, invest the same amount of resources in governance quality and, at the same time, spend effort and resources in a way that poverty increases (of course, one measure of good governance can be poverty reduction). In other words, such a policy driven by the donor country will increase poverty.

If the donor introduces a condition under which the portion of aid received by a country is a function of the poverty of a country then this will induce the country to invest in ways that will increase poverty while at the same time increase resources invested in governance quality. Such a system will create a poverty trap causing the leaders of the countries to invest in order to raise the poverty level to obtain a higher proportion of the aid.

\section{Conclusion}

The donor may have a particular goal in its aid program, or it may be trying to satisfy 
multiple objectives. To achieve these goals the donor may need to encourage change in recipient behavior. However, recipients are not passive. They have objectives of their own; in particular, their leaders may have their own programs. To simplify the discussion in this paper we assume the donor government believes that its multiple goals can be achieved by first ensuring there is good governance in the recipient country - and with-holding aid until that time. What drives our model is the donors' desire for good governance and local leaders' desire for long term gain. Our main result is that the donor country will prefer the system under which the aid will all go to only one country while the leaders of the receiving countries will prefer that each country will obtain the proportion of aid relative to its governance quality. We also separate out the desire of the donor for poverty reduction, a consequence of which may be the development of a poverty trap. In order to continue to receive transfers based on poverty a potential recipient government may deliberately allocate funds away from the poorest so as not to better their position. Incentives often work in nonobvious ways. 


\section{References}

Baye, Michael R., Dan Kovenock, and Casper G. de Vries. 1993. Rigging the lobbying process: an application of the all-pay auction. American Economic Review 83(1):289-294.

Che, Yeon. and Ian Gale. 1998. Caps on political lobbying. American Economic Review 88(3):643-651.

Ellingsen, Tore. 1991. Strategic buyers and the social cost of monopoly. American Economic Review 81(3):648-657.

Epstein Gil S. and Ira N. Gang. 2006. Contests, NGOs and decentralizing aid. Review of Development Economics 10(2):285-206.

Epstein Gil S. and Shmuel Nitzan, 2006a. Effort and performance in public policy contests. Journal of Public Economic Theory 8(2):265-282.

Epstein Gil S. and Shmuel Nitzan. 2006b. Reduced prizes and increased effort in contests. Social Choice and Welfare, forthcoming.

Epstein, Gil S. 2000. Personal productivity and the likelihood of electoral success of political candidates. European Journal of Political Economy 16(1): 95-111.

Heckelman, Jac and Stephen Knack. 2005. Foreign aid and market-liberalizing reform. World Bank Policy Research Working Paper 3557, April.

Hillman, Arye L. and John G. Riley. 1989. Politically contestable rents and transfers. Economics and Politics 1(1):17-39.

Lockard, Alan A; Tullock, Gordon, eds. 2001. Efficient rent-seeking, chronicle of an intellectual quagmire. Boston: Kluwer Academic Publishers.

Mavrotas, George and Espen Villanger. 2006. Multilateral aid agencies and strategic donor behaviour. Discussion Paper 2006/02. UNU-WIDER, Helsinki, Finland.

McGillivray, Mark, Simon Feeny, Niels Hermes and Robert Lensink. 2005. It works; it doesn't; it can, but that depends.” Research Paper 2005/54. UNU-WIDER, Helsinki, Finland.

Nitzan, Shmuel. 1994. Modelling rent-seeking contests. European Journal of Political Economy 10(1): 41-60 (also appears in Lockard and Tullock (2001)).

Tullock, Gordon. 1980. Efficient rent-seeking. In Toward a theory of the rent-seeking society, edited by J.M. Buchanan, R.D. Tollison, and G. Tullock, 97-112. College Station, TX: Texas A. and M. University Press. 